\title{
User Curated Augmented Reality Art Exhibitions
}

\begin{tabular}{|c|c|}
\hline Paul Coulton & Richard Smith \\
\hline Imagination & Live At LICA \\
\hline Lancaster University, & Lancaster Universit \\
\hline Lancaster, UK. & Lancaster, UK. \\
\hline p.coulton@lancaster.ac.uk & prichard@liveatlica.org \\
\hline Emma Murphy & Mark Lochrie \\
\hline Glasgow School of Art & Imagination \\
\hline Glasgow, UK. & Lancaster Unive \\
\hline Emma.murphy@gsa.ac.uk & Lancaster, UK. \\
\hline Klen Čopič Pucihar & \\
\hline School of Computing and & \\
\hline Communications & \\
\hline Lancaster University, & \\
\hline Lancaster, UK & \\
\hline k.copicpuc@lancaster.ac.uk & \\
\hline \multicolumn{2}{|c|}{$\begin{array}{l}\text { Permission to make digital or hard copies of part or all of this work for } \\
\text { personal or classroom use is granted without fee provided that copies are } \\
\text { not made or distributed for profit or commercial advantage and that } \\
\text { copies bear this notice and the full citation on the first page. Copyrights } \\
\text { for third-party components of this work must be honored. For all other } \\
\text { uses, contact the Owner/Author. }\end{array}$} \\
\hline \multicolumn{2}{|c|}{ Copyright is held by the owner/author(s). } \\
\hline \multicolumn{2}{|c|}{$\begin{array}{l}\text { NordiCHI '14, Oct } 26-302014 \text {, Helsinki, Finland } \\
\text { ACM } 978-1-4503-2542-4 / 14 / 10 \text {. } \\
\text { http://dx.doi.org/10.1145/2639189.2670190 }\end{array}$} \\
\hline
\end{tabular}

\begin{abstract}
Creating mobile augmented reality applications to display gallery artworks or museum content is a wellestablished concept within the research community. However, the focus of these systems is generally technologically driven and primarily addresses the end user and not the views of the gallery or the original artist. In this paper we present the design and development of the mobile application 'Taking the Artwork Home', which allows people to digitally curate augmented reality art exhibitions in their own homes. A research through design methodology was adopted so that we could more fully understand how the views of the gallery and artists impacted on the artifact design and therefore the user experience.
\end{abstract}

\section{Author Keywords}

design, research through design, augmented reality, mobile, art curation.

\section{ACM Classification Keywords}

H.5.m. Information interfaces and presentation

\section{Introduction}

Augmented Reality (AR) research has created a number of applications aimed at addressing the needs of the cultural sector predominantly either as guides for cultural sites $[5,2,7,6]$, to provide alternate 
representations of the museum content, or as a nove means of providing additional meta-data [1]. The mobile AR application, 'Taking the Artwork Home', developed during this research is currently focused on paintings and photographs and other research has considered AR in this context to view artworks [4], create artworks [6], and even provide alternate infrared or ultra-violet $[4,8]$ views of a painting. However, whilst this previous research has been technologically driven, or only addresses the end user, in this research we adopted a research for design approach with a range of stakeholders where we adhere to Sir Christopher Frayling's definition of research through design in that we are reflecting on the process to recommend what is both desirable and productive for future practice. However, it could also be classed as research for design [3] as the end product is a prototype artifact in that all the thinking that went into producing it is embedded within it, and in the sense that it is not simply finished ready-to-market app, but more an artifact in perpetual beta with implications for designers to take further.

\section{Design Methodology}

The 'Taking the Artwork Home' app has not been designed to operate within the existing physical gallery but rather it allows users to engage with the gallery content in their own home. It builds on existing work aimed at encouraging public engagement with more of the gallery's collection than may be on public display at a given time. By providing an experience of viewing artwork situated in physical space, we can most closely recreate what a user might experience in a real gallery. While it is hoped that AR experience encourages users to consider visiting the physical gallery, the data generated by users also provides valuable insights in what aspects of the collection people find interesting.

The research through design methodology was developed using an iterative participatory design approach whereby a number of prototypes were presented to the gallery and artists together with a range of potential user groups of between 8-20 people for feedback and discussion. The prototypes explored the users experience in a number of areas that related particularly to the major concerns of the galley and artists around image rights management. The rights management issues resulted in prototypes that addressed image resolution and comparisons between on-device and cloud implementations for tracking and image storage.

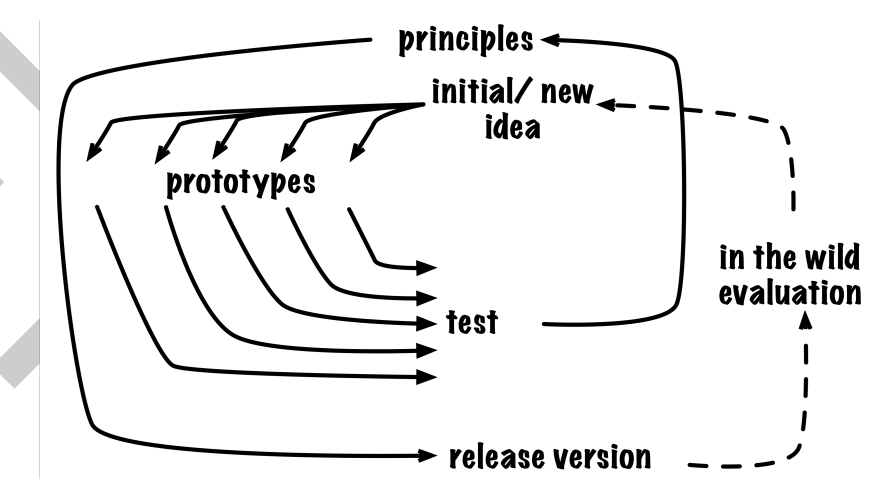

Figure 1. Application Research and Development Process.

The users groups included volunteers and patrons of the gallery, children from local schools varying in age 6-18, and a local college that provides courses for learners between 18 and 25 with a broad range of physical and learning disabilities. Within these sessions 
we provided these users with a range of devices running the application and only gave instructions for how to start the application. During these sessions we asked users to speak aloud their thoughts, which were recorded, and at the end of the sessions we held group discussions to capture what they liked/disliked about the application and potential new features they thought could improve the application. After testing and evaluation of the prototypes with over 100 users we developed the principles that guided the design of the application released on the App store. Note that as Figure 1 shows this is not the end of the research process as it has now entered an 'in the wild' evaluation phase that will inform subsequent versions.

\section{Application Design}

The application has been designed to provide a good user experience whilst emphasizing the link between the artwork and the gallery. This is incorporated within the different functionality: create an exhibition, view exhibition, help, settings, being represented as paintings in a gallery.

Create Exhibitions

In the current version, the number of artworks that can be incorporated by the user has been restricted to three, reduce complexity as shown in Figure 2 . The order of selection corresponds to the order in which the user defines their own three AR markers as shown in Figure 3 , or it uses the three default markers which can be downloaded by the user. Having selected their chosen artworks the user gives the exhibition a name and description. At this point the user can also define how they wish the artwork to be displayed in relation to the AR marker. They can choose either to display either: proportional to the height of the marker; proportional to the width of the marker; display at the original dimensions; define a custom display size.
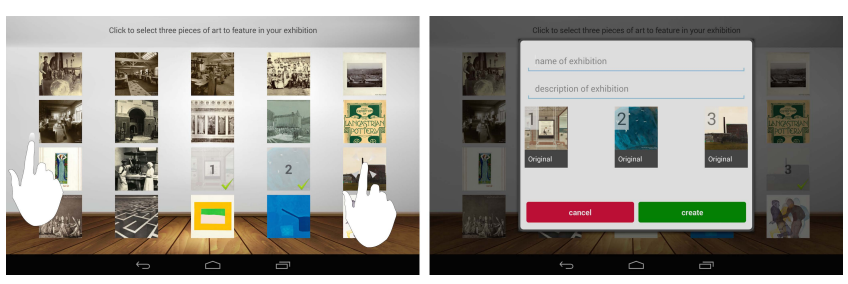

Figure 2. Create Exhibition.
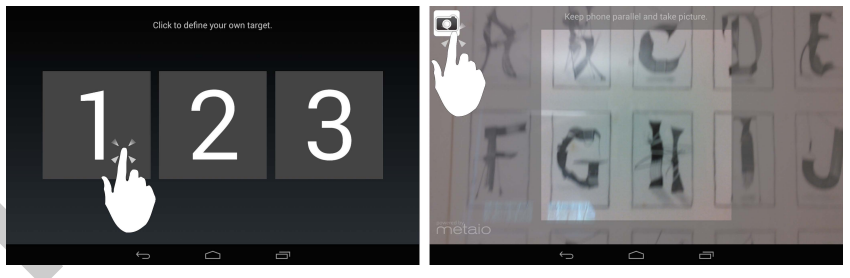

gire 3. Define AR Markers.

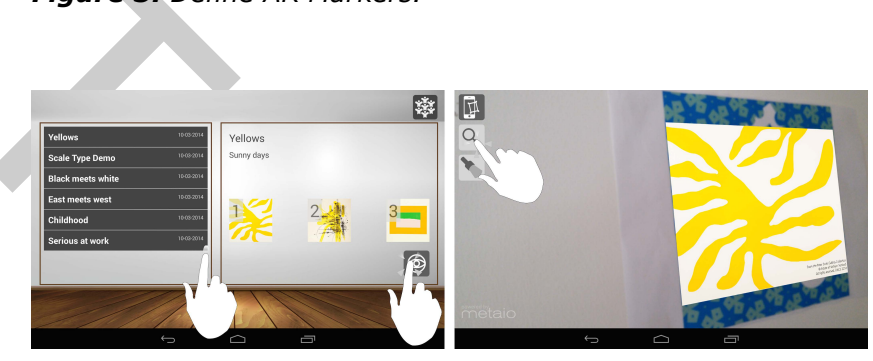

Figure 4. View Exhibition.

\section{View Exhibitions}

The view exhibition allows the user to select from either there own exhibitions or from the others created by the 
community. The user simply presses the view button to enter AR mode to view the images. The application is set-up so that the default is to use the three AR markers we created for the project, and are available to download by the user, or the user can define three markers of their own in the settings menu.

\section{Conclusion}

In this research we have considered the implications of designing mobile AR applications using content from museums and galleries, not from a primarily technologically driven perspective but rather one that includes the users, artists and galleries. This led to a research for design approach utilizing iterative prototypes. This allowed us to explore aspects of the design driven by the concerns artists and gallery that directly affected the user experience we were able to create.

We are currently gaining the rights to add works images to this application which will now form the basis of a longitudinal study in which we will evaluate the data generated by users with the intention this can be used by the gallery to better inform their future exhibitions.

\section{Acknowledgements}

This project is supported through the Digital R\&D Fund for the Arts - Nesta, Arts \& Humanities Research Council and public funding by the National Lottery through Arts Council England.

\section{References}

[1] Angelopoulou, A., Economou, D. Bouki, V., Psarrou, A., Jin, L., Pritchard, C., and Kolyda, F. Mobile
Augmented Reality for Cultural Heritage. In Mobile Wireless Middleware, Operating Systems, and Applications, Springer Berlin Heidelberg, 2012, pp. 1522.

[2] Caarls, J., Jonker, P., Kolstee, Y., Rotteveel, J., and van Eck, W. Augmented Reality for Art, Design and Cultural Heritage-System Design and Evaluation,

EURASIP Journal on Image and Video Processing, vol. 2009, Article ID 716160, 16 pages.

[3] Frayling, C. Research Papers, "Research in Art and Design", Royal College of Art, Vol. 1 no. 1, 1994, pp. 15.

[4] Kolstee, Y., and van Eck, W. The Augmented Van Gogh's: Augmented Reality Experiences for Museum Visitors. Mixed and Augmented Reality-Arts, Media, and Humanities, 2011 IEEE International Symposium On research, technology and application in Mixed and Augmented Reality, Basel, pages 29-52, October 2011.

[5] Miyashita, T., Meier, P., Tachikawa, T., Orlic, S., Eble, T., Scholz, V., Gapel, A., Gerl, O., Arnaudov, S. and Lieberknecht, S. 2008. An Augmented Reality museum guide. In Proceedings of the 7th IEEE/ACM International Symposium on Mixed and Augmented Reality (ISMAR '08). IEEE Computer Society, Washington, DC, USA, 2008, 103-106.

[6] Papagiannakis, G., Schertenleib, S., O'Kennedy, B., Arevalo-Poizat, M., Magnenat-Thalmann, N., Stoddart, A., \& Thalmann, D. (2005). Mixing Virtual and Real scenes in the site of ancient Pompeii. Computer Animation and Virtual Worlds, 16(1), 2005, 11-24. [7] Tillon, A. B., Marchal, I., \& Houlier, P. (2011, October). Mobile augmented reality in the museum: Can a lace-like technology take you closer to works of art? In Mixed and Augmented Reality-Arts, Media, and Humanities, ISMAR 2011, pp. 41-47.

[8] van Eck, Wim, and Kolstee, Y. The augmented painting: Playful interaction with multi-spectral images. ISMAR 2012. 